\title{
Measurement of the Parameters of Pulse Rate Variability (Resting Test, Orthostatic Test, Metronomic Breathing Test) After Intake of 1 and 3 Cups of Instant Coffee in A 60-Year-Old Man
}

\author{
Ivan Domuschiev* \\ Department of Internal Diseases, Plovdiv City, Bulgaria
}

*Corresponding author: Ivan Domuschiev, Multiprofile Transport Hospital, Department of Internal Diseases, Plovdiv City, Bulgaria

\begin{tabular}{|c|c|}
\hline ARTICLE INFO & ABSTRACT \\
\hline $\begin{array}{l}\text { Received: May 17, } 2021 \\
\text { Published: 幽 May 25, } 2021\end{array}$ & $\begin{array}{l}\text { Citation: Ivan Domuschiev. Measurement of the Parameters of Pulse Rate Variability } \\
\text { (Resting Test, Orthostatic Test, Metronomic Breathing Test) After Intake of } 1 \text { and } 3 \text { Cups } \\
\text { of Instant Coffee in A 60-Year-Old Man. Biomed J Sci \& Tech Res 36(1)-2021. BJSTR. } \\
\text { MS.ID.005793. }\end{array}$ \\
\hline
\end{tabular}

\section{Case Report}

The Pulse Rate Variability (PRV) is a very valuable quantitative method for studying the reactions of the two departments (sympathetic and parasympathetic) of the autonomic nervous system to various factors and substances. The parameters of the Pulse Rate Variability (PRV) were measured in a 60-year-old man with a height of $178 \mathrm{~cm}$, weight $75 \mathrm{~kg}$ and $\mathrm{BMI}=24$. The measurement was performed using a PPG sensor placed on the finger of the left hand (Heart Rhythm Scanner - Biocom Technologies - USA). The first HRV measurement was taken at rest 45 minutes after consuming 1 cup of instant coffee in the morning after sleep (see Figure 1). The second PRV test was done after consuming 2 more cups of instant coffee. It includes resting measurements and a orthostatic test (see Figure 2). The third measurement was performed after the second study. It includes measurement of PRV parameters at rest and a metronomic breathing test (see Figure 3). All these data show the changes in PRV after consuming 1 cup of instant coffee and after 3 cups of instant coffee. From this one can get an idea of how instant coffee affects PRV [1-8].

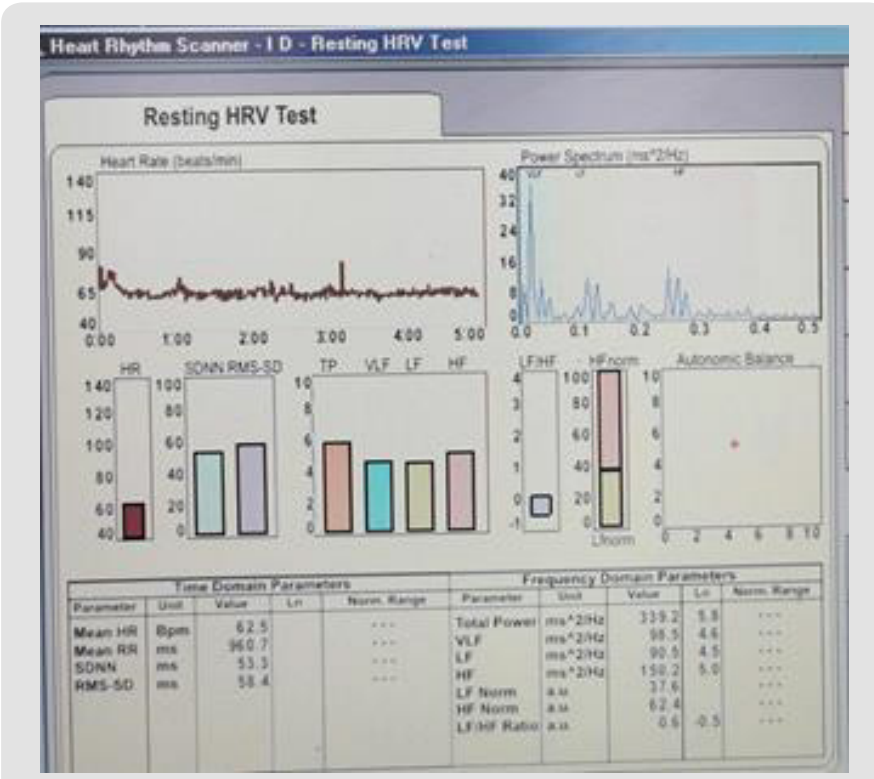

Figure 1. 


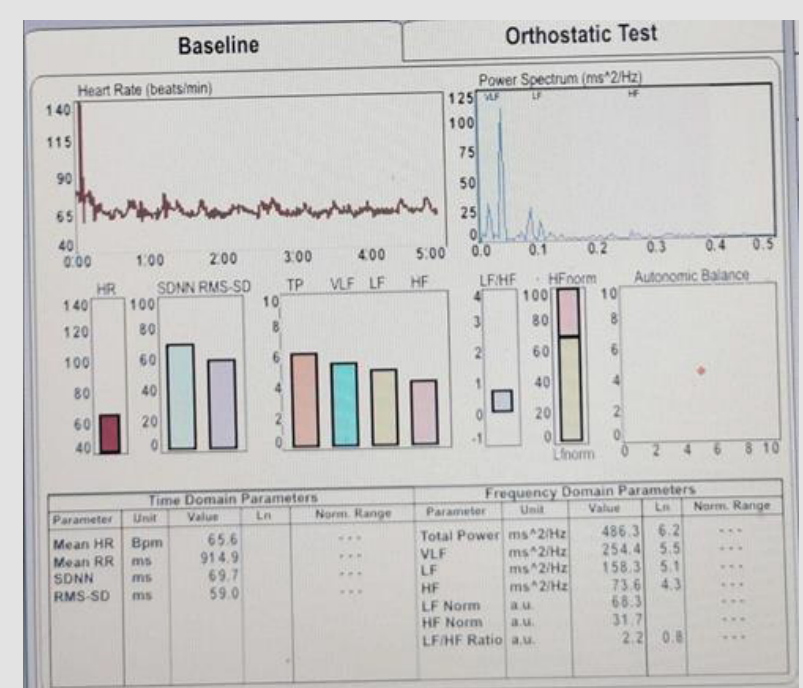

Figure 2.

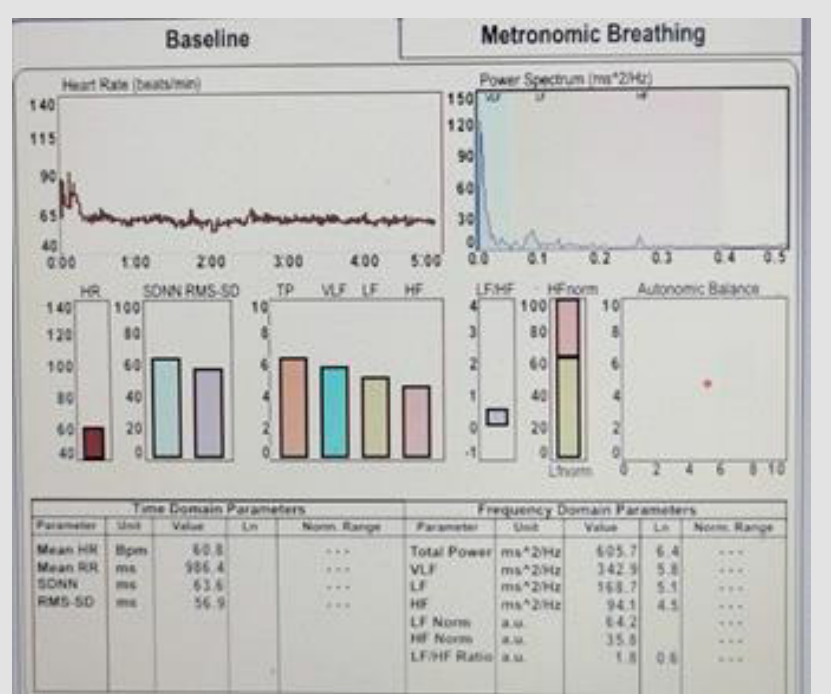

Figure 3.

\section{References}

1. Rackel Aguiar Mendes de Oliveira, Larissa FA, Roberta CF, Alessandra CG, Maria IS, et al. (2017) Coffee Consumption and Heart Rate Variability: The Brazilian Longitudinal Study of Adult Health (ELSA-Brasil) Cohort Study, Nutrients 9(7): 741.

2. G Hibino, Moritani T, Kawada T, Fushiki T (1997) Caffeine enhances modulation of parasympathetic nerve activity in humans: quantification using power spectral analysis, J Nutr 127(7): 1422-1427.

3. Monda M, An V, C Vicidomini, Al Viggiano, T Innaccone, et al. (2009) Espresso coffee increases parasympathetic activity in young, healthy people, Nutr Neurosci 12(1): 43-48.

4. Frank Zimmermann-Viehoff, Julian FT, Julian K, Christian H, Cora SW, et al. (2016) Short-term effects of espresso coffee on heart rate variability and blood pressure in habitual and non-habitual coffee consumers--a randomized crossover study, Nutr Neurosci 19(4): 169-175.

5. Amir Sarshin, A Naderi, Carlos JG, Foad F, Scott CF, et al. (2020) The effects of varying doses of caffeine on cardiac parasympathetic reactivation following an acute bout of anaerobic exercise in recreational athletes, J Int Soc Sports Nutr.

6. Rauh R, Burkert M, Siepmann M, Mueck-Weymann M (2006) Acute effects of caffeine on heart rate variability in habitual caffeine consumers. Clin. Physiol. Funct. Imaging 26(3): 163-166.

7. Zimmermann Viehoff F, Thayer J, Koenig J, Herrmann C, Weber CS, et al. (2016) Short-term effects of espresso coffee on heart rate variability and blood pressure in habitual and non-habitual coffee consumers-A randomized crossover study. Nutr. Neurosci 19(4): 169-175.

8. Notarius CF, Floras FJ (2012) Caffeine Enhances Heart Rate Variability in Middle-Aged Healthy, But Not Heart Failure Subjects. J. Caffeine Res 2(2): 77-82.

\section{ISSN: 2574-1241}

DOI: 10.26717/BJSTR.2021.36.005793

Ivan Domuschiev. Biomed J Sci \& Tech Res

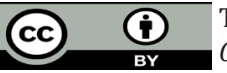

This work is licensed under Creative Commons Attribution 4.0 License

Submission Link: https://biomedres.us/submit-manuscript.php

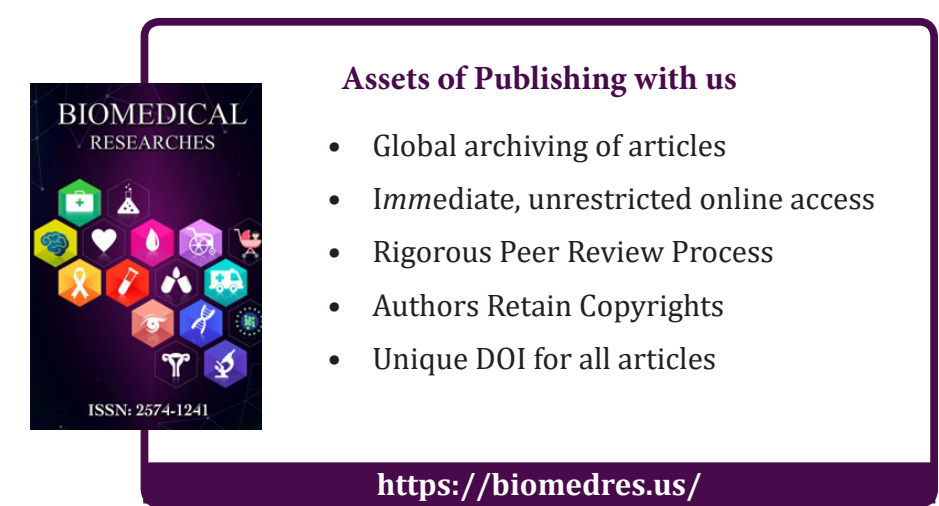

